\title{
The Pursuit of Professional Practice Excellence and the Achievement of Peer Recognition
}

\author{
Glen J Pearson
}

\begin{abstract}
Don't worry when you are not recognized, but strive to be worthy of recognition.
\end{abstract} - Abraham Lincoln

W ith the awards season in full swing, it is important to remember that the goal of the Canadian Society of Hospital Pharmacists (CSHP) National Awards Program is to improve patient outcomes by promoting excellence in the practice of pharmacy throughout hospitals and other collaborative health care settings. During the Professional Practice Conference in Toronto, outstanding individual practitioners and teams from across the country will have been recognized for their outstanding commitment to the profession and their patients.

CSHP offers 2 types of member awards. The General Awards Program recognizes practitioners who have completed projects deemed to be innovative and of importance to pharmacy practice in hospitals and other collaborative health care settings, in 7 categories. The Special Awards Program recognizes members who have distinguished themselves within the profession over time (Distinguished Service and Isabel E. Stauffer Meritorious Service awards) or who show a commitment to practice excellence and professional development early in their hospital pharmacy career (student and new practitioner awards).

Another important longitudinal recognition program is the CSHP Fellowship Program. The status of Fellow (FCSHP) is conferred upon members who have demonstrated sustained, noteworthy service and excellence in the practice of pharmacy in an organized health care setting.

The awards program is accessible to all CSHP members, but only a small proportion of people ever apply or are nominated. Nevertheless, we all benefit from the successes of these innovative and leading practitioners - their efforts provide practical examples of how we each can practice to the best of our abilities and help our patients achieve their desired health outcomes.

It should be no surprise that selecting the recipients of these awards is a challenge. Each nominee or project is appraised against a set of award-specific criteria, but the final selection may be limited by the quality of the application materials submitted. So, when you step forward and apply for a CSHP award, ensure that your application adheres to the submission requirements and is presented in a manner that demonstrates exactly how you or the project fulfill the criteria.

Why do relatively few members apply for awards, when clearly there are so

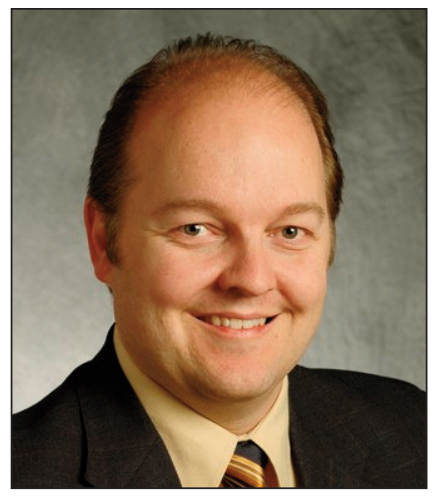
many deserving individuals within our ranks? Perhaps many practitioners simply do not believe they are worthy of recognition for their work or achievements. Although humility is a personal characteristic revered among pharmacists, it is a passive characteristic that may impede our own self-efficacy. Recognition and awards are not what motivates each of us to strive for excellence in our daily practice, but we should remember that these programs serve a greater good. Even if you do not consider yourself worthy of recognition, consider your work worthy of sharing with other members of our Society.

The CSHP awards and recognition programs acknowledge members' excellence in hospital pharmacy practice, improve patient care, promote and support career development of pharmacists in organized health care settings, and enhance the reputation and value of CSHP members. Do not miss out on the opportunity to help CSHP achieve these goals. While your patients appreciate and benefit from your daily pursuit of excellence, please consider sharing your successes. Let us honour and celebrate all of our members for their achievements and their ongoing pursuit of professional practice excellence. Whether or not you are individually recognized, your patients, colleagues, and students all benefit from your commitment to excellence. Congratulations!

Glen J Pearson, BSC, BScPhm, PharmD, FCSHP, FCCS, is Past-President and External Liaison for the Canadian Society of Hospital Pharmacists. 